\title{
A New Fracture Detection Algorithm of Low Amplitude Acoustic Emission Signal Based on Kalman Filter-Ripple Voltage
}

\author{
Seong-Min Jeong ${ }^{1}$, Seokmoo Hong ${ }^{1,2, *(D)}$ and Jong-Seok Oh 1,2,*(D) \\ 1 Department of Future Convergence Engineering, Kongju National University, Cheonan 31080, Korea; \\ tjdals7699@gmail.com \\ 2 Department of Future Automotive Engineering, Kongju National University, Cheonan 31080, Korea \\ * Correspondence: smhong@kongju.ac.kr (S.H.); jongseok@kongju.ac.kr (J.-S.O.)
}

Citation: Jeong, S.-M.; Hong, S.; Oh, J.-S. A New Fracture Detection Algorithm of Low Amplitude Acoustic Emission Signal Based on Kalman Filter-Ripple Voltage. Sensors 2021, 21, 4247. https://doi.org/ $10.3390 / \mathrm{s} 21124247$

Academic Editor:

Dimitrios G. Aggelis

Received: 25 May 2021

Accepted: 15 June 2021

Published: 21 June 2021

Publisher's Note: MDPI stays neutral with regard to jurisdictional claims in published maps and institutional affiliations.

Copyright: (c) 2021 by the authors. Licensee MDPI, Basel, Switzerland. This article is an open access article distributed under the terms and conditions of the Creative Commons Attribution (CC BY) license (https:// creativecommons.org/licenses/by/ $4.0 /)$.

\begin{abstract}
In this study, an acoustic emission (AE) sensor was utilized to predict fractures that occur in a product during the sheet metal forming process. An AE activity was analyzed, presuming that AE occurs when plastic deformation and fracturing of metallic materials occur. For the analysis, a threshold voltage is set to distinguish the AE signal from the ripple voltage signal and noise. If the amplitude of the AE signal is small, it is difficult to distinguish the AE signal from the ripple voltage signal and the noise signal. Hence, there is a limitation in predicting fractures using the AE sensor. To overcome this limitation, the Kalman filter was used in this study to remove the ripple voltage signal and noise signal and then analyze the activity. However, it was difficult to filter out the ripple voltage signal using a conventional low-pass filter or Kalman filter because the ripple voltage signal is a high-frequency component governed by the switch-mode of the power supply. Therefore, a Kalman filter that has a low Kalman gain was designed to extract only the ripple voltage signal. Based on the KF-RV algorithm, the measured ripple voltage and noise signal were reduced by $97.3 \%$ on average. Subsequently, the AE signal was extracted appropriately using the difference between the measured value and the extracted ripple voltage signal. The activity of the extracted AE signal was analyzed using the ring-down count among various AE parameters to determine if there was a fracture in the test specimen.
\end{abstract}

Keywords: Kalman filter; ripple noise; acoustic emission; fracture detection; press process

\section{Introduction}

The occurrences of defects in sheet metal formation can cause huge losses in productivity. Furthermore, if sheet metal forming tasks are performed without detecting defects in the die, the die itself could be damaged. Therefore, to develop a system for identifying defects in sheet metal forming, several studies have been conducted in recent years to develop a defect detection system that utilizes a new inspection method based on acoustic emission [1-3].

Acoustic emission (AE) refers to an acoustic signal that is generated when the strain energy that is formed locally in a solid material is rapidly released [4]. AE is used for detecting predicted fractures in bearings [5], gearboxes [6], pressure vessels [7], and pipes [8,9] at many sites in the industry. Moreover, an AE signal is generated when an object is plastically deformed or fractured. When a metallic material exceeds the maximum load and is close to fracturing, AE occurs frequently. Hence, AE is widely applied for evaluating the mechanical properties of materials [10-14].

The analysis method of such an AE signal can be largely divided into waveform analysis related to the activity and the shape of the signal [10,15]. The AE activity analysis method evaluates various parameters such as the number of events, ring-down count, and maximum amplitude. The analysis method is directly related to the size and frequency of 
the source of the AE. In Figure 1, the ring-down count refers to the number of AE vibrations that cross the detection threshold. On the contrary, the method based on waveform analysis compares the waveform shapes of the AE signals. The parameters utilized in this method include duration time and frequency spectrum. Duration time refers to the time elapsed between the time the wave height first exceeds the threshold voltage and the time the wave height is less than the threshold voltage from the same AE event.

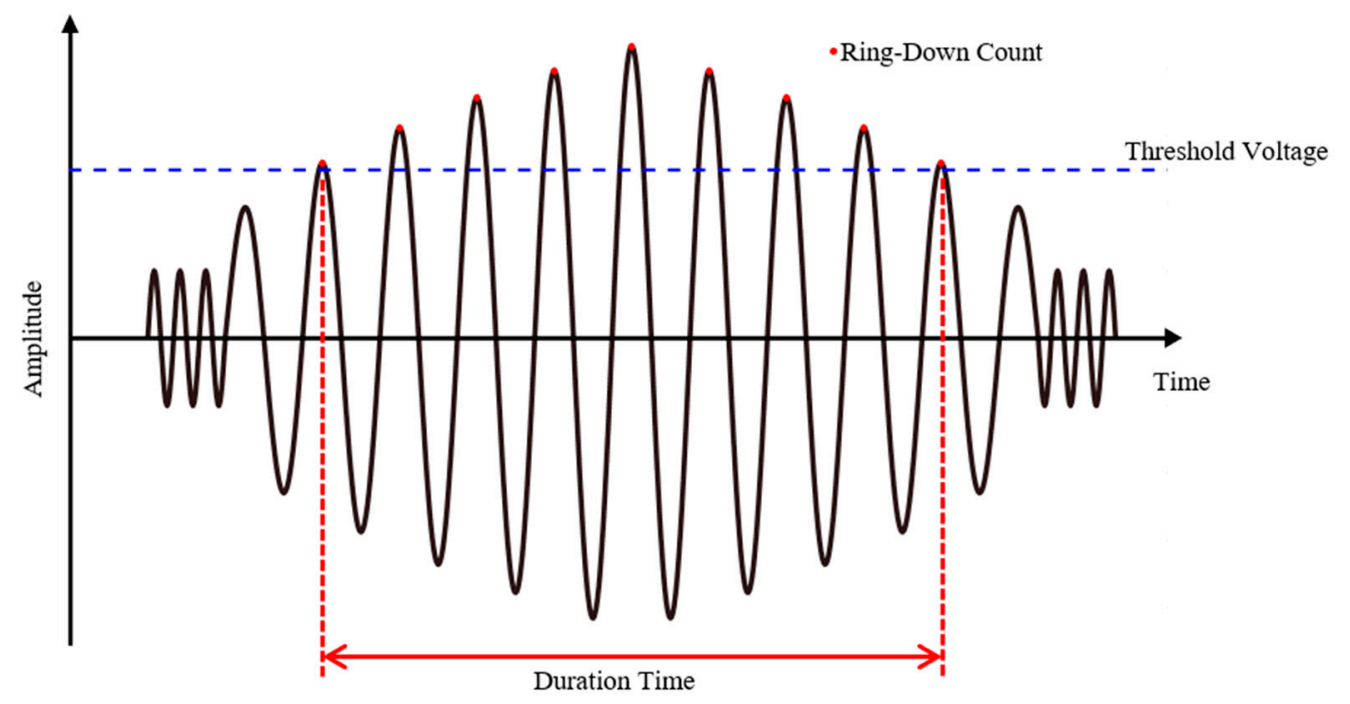

Figure 1. AE parameter.

To apply the AE signal analysis method to real manufacturing processes, it is essential to distinguish the noise or ripple voltage signal from the AE signal [16-19]. Hence, a trigger algorithm using the threshold voltage value [20-23] and a low-pass filter that removes high-frequency noise [24] have been widely applied. The threshold voltage is a voltage that recognizes the $\mathrm{AE}$ signal. The value of the threshold voltage should be set considering the magnitude of the surrounding noise and the magnitude of the AE signal.

However, even these suggested algorithms have considerable difficulty detecting an $\mathrm{AE}$ signal because the $\mathrm{AE}$ signal for ductile materials has a very high signal-to-noise ratio (SNR) at factories where sheet metal forming is performed [4,25]. As shown in Figure 2, the AE signal amplitude is closely related to the crack growth speed. Due to the crack growth speed of brittle materials being very high, as shown in Figure 2a, the signal amplitude is large. However, the fracture toughness of ductile materials is very large, as shown in Figure $2 b$. The generation and growth of the crack occur very slowly, and the signal amplitude is relatively small. Hence, the application of the AE sensor for ductile materials was limited by the low amplitude signal and inevitable noise. Previous studies related to the press process show good results for little SNR, whereas the relatively poor detection performance was obtained from the material with high SNR [1-3].

Moreover, power must be supplied to actuate the $\mathrm{AE}$ sensor, and the ripple voltage signal of the power supply is transmitted as the output through various paths. In a switchmode power supply, a switching regulator receives power from an alternating current (AC) power source and converts it to direct current (DC) to supply the power. Here, the AC is not entirely converted to $\mathrm{DC}$, and the remaining $\mathrm{AC}$ signal is known as the ripple voltage signal $[26,27]$. The ripple voltage signal follows the driving frequency of the switching regulator, and this frequency is higher than the frequency of the AE signal. Hence, it is difficult to cancel the ripple voltage signal using a low-pass filter. The ripple voltage signal from the power supply is a factor that further restricts the use of $\mathrm{AE}$ sensors that have a low voltage signal value. To distinguish the $\mathrm{AE}$ signal from ripple voltage and noise signals, a deep learning algorithm such as the convolutional neural network (CNN) method can be applied. From the results in previous studies [28-30], it has been proved that the deep 
learning method shows a good detection performance. However, since the CNN method requires a frequency domain image file such as spectrogram or scalogram, it cannot detect the failure of the system in real-time. It is very important to detect the occurrences of defects in the manufacturing field in real-time and even early. Therefore, in this study, a Kalman filter was applied with a low Kalman gain to an algorithm that processes $\mathrm{AE}$ signals containing noise and ripple voltage signals to predict fractures in ductile materials during sheet metal forming.

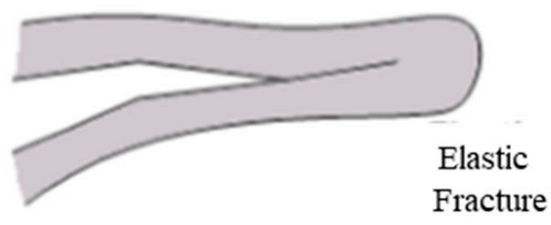

Brittle Crack

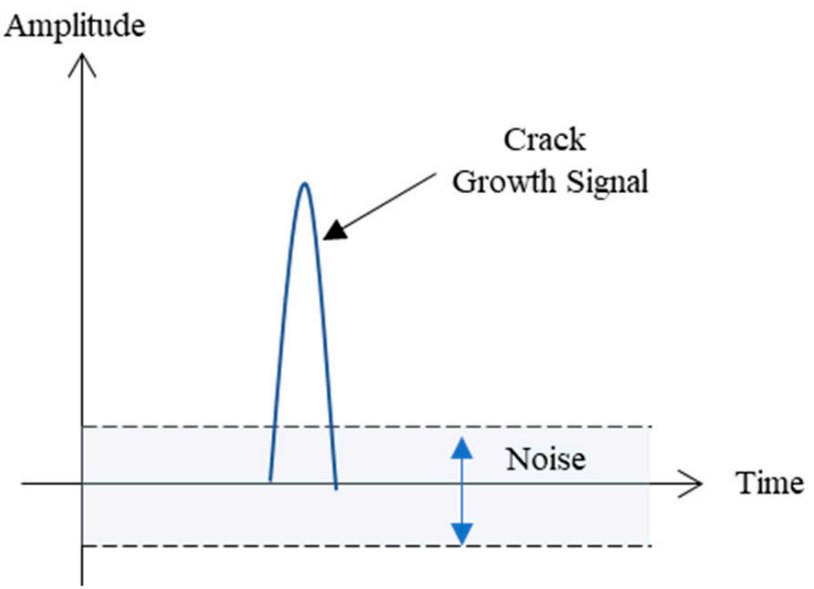

(a) AE signal characteristics of brittle materials.
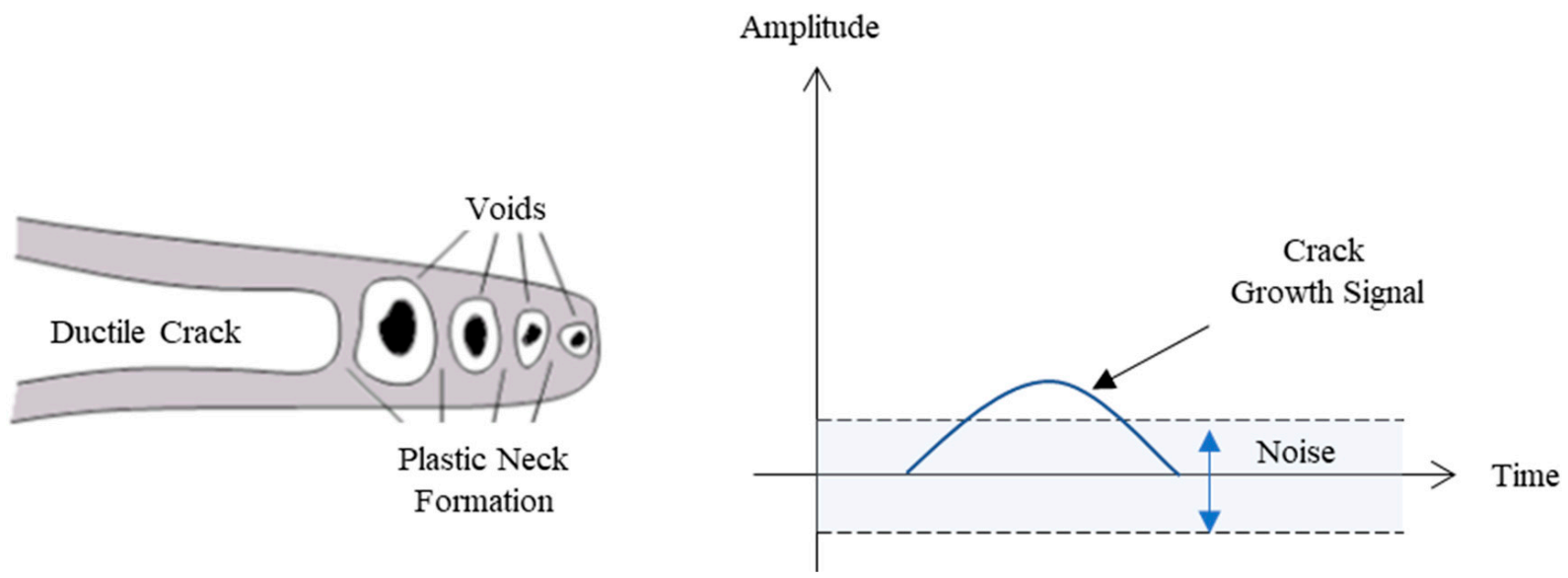

(b) AE signal characteristics of ductile materials.

Figure 2. AE signal amplitude according to fracture characteristics.

Although the AE sensor has been applied to many applications in the manufacturing process, it has not yet been applied to the metal sheet forming process for a ductile material. The advantage of the proposed method is to detect the defect of the material, which has a very high $\mathrm{AE}$ signal-to-noise ratio in real-time. The noise makes it difficult to detect the fracture of the specimen by using the $\mathrm{AE}$ sensor. Moreover, the ripple voltage is unavoidable for the measurement system with a power supply. Many previous studies focus on materials that have a low AE signal-to-noise ratio. Therefore, the primary purpose of this manuscript is to explore the potentials of KF-RV as a fracture detection method for the metal sheet forming process. Therefore, in this study, a Kalman filter with a low Kalman gain was applied to the AE signal processing algorithm to predict fractures in ductile materials during sheet metal forming. In order to prove this, the authors present the simulation results for virtually synthesized signals. The proposed estimation algorithm and simulation results are presented in the section: Design of Kalman Filter-Ripple Voltage. Next, the sheet metal forming process is experimentally conducted by using a pressing device, and the raw sensor data is measured, as described in the section: Sheet Metal 
Forming Experiment. Finally, in the section: AE Detection Method and Discussion, it has been confirmed that the $\mathrm{AE}$ detection method can determine the accurate time at which a defect occurs in the product during the sheet metal forming process.

\section{Design of Kalman Filter-Ripple Voltage}

In this study, the Kalman filter was applied to the signal-processing algorithm of an $\mathrm{AE}$ sensor. The Kalman filter is divided into two stages-estimating the current state and estimating the Kalman gain using the measured value. In the current state estimation stage, the previous value is used to predict the next value, and the error covariance is used to estimate the value for the subsequent period. In the Kalman gain estimation stage, a new value is included in the previous value to obtain the supplemented subsequent value. The discrete-time state-space model of the AE sensor is defined as follows for the Kalman filter design [31-34].

$$
\begin{aligned}
& \mathbf{x}(k+1)=\mathbf{A}_{d} \mathbf{x}(k)+\mathbf{w}(k) \\
& z(k)=\mathbf{H} x(k)+v(k) \\
& \mathbf{A}_{d}=\left[\begin{array}{cc}
1 & T_{a} \\
0 & 1
\end{array}\right], \mathbf{H}=\left[\begin{array}{ll}
1 & 0
\end{array}\right], \mathbf{x}(k)=\left[\begin{array}{ll}
a(k) & \dot{a}(k)
\end{array}\right]^{T}
\end{aligned}
$$

where, $z$ is the measured value from the sensor, $\mathbf{A}_{d}$ is the system matrix of the discrete system, and $\mathbf{H}$ is the measurement matrix. $\mathbf{w}$ and $v$ denote the noise matrices of the system and measurement model, respectively, and they are assumed to be Gaussian noises. $\mathbf{x}(k)$ is the state vector matrix. $T_{a}$ is the sampling time. In this study, $T_{a}$ is assigned a value of $500 \mathrm{kHz}$. The subscript $d$ denotes the discrete-time, and the Kalman filter is designed based on the discrete-time measurement model, as shown below.

- Prediction Stage

$$
\begin{aligned}
\hat{\mathbf{x}}(k+1 \mid k) & =\mathbf{A}_{d} \hat{\mathbf{x}}(k \mid k) \\
\mathbf{P}(k+1 \mid k) & =\mathbf{A}_{d} \mathbf{P}(k \mid k) \mathbf{A}_{d}^{T}+\mathbf{Q}_{d}
\end{aligned}
$$

- Kalman gain calculation stage

$$
\mathbf{K}(k+1)=\mathbf{P}(k+1 \mid k) \mathbf{H}^{T}\left[\mathbf{H} \mathbf{P}(k+1 \mid k) \mathbf{H}^{T}+\mathbf{R}_{d}\right]^{-1}
$$

- Correction stage

$$
\begin{aligned}
& \hat{\mathbf{x}}(k+1 \mid k+1)=\hat{\mathbf{x}}(k+1 \mid k)+\mathbf{K}(k+1)[z(k+1)-\mathbf{H} \hat{\mathbf{x}}(k+1 \mid k)] \\
&=\mathbf{K}(k+1) z(k+1)+(1-\mathbf{K}(k+1) \mathbf{H}) \hat{\mathbf{x}}(k+1 \mid k) \\
& \mathbf{P}(k+1 \mid k+1)=[\mathbf{I}-\mathbf{K}(k+1) \mathbf{H}] \mathbf{P}(k+1 \mid k)
\end{aligned}
$$

where, $\mathbf{Q}_{d}$ is the covariance matrix of system noise, $\mathbf{R}_{d}$ is the covariance matrix of measurement noise, and $\mathbf{K}$ is the Kalman gain. $\hat{\mathbf{x}}(k+1 \mid k)$ is the pre-estimated state vector matrix and $\mathbf{P}(k+1 \mid k)$ is the pre-estimated error covariance matrix. These matrices are used to estimate the state vector matrix $\hat{\mathbf{x}}(k+1 \mid k+1)$ and error covariance matrix $\mathbf{P}(k+1 \mid k+1)$ in the next stage. Moreover, $\mathbf{Q}_{d}$, which was used to estimate the error covariance, is a system model parameter. As the value of $\mathbf{Q}_{d}$ increases, the effect of the measured value increases. Likewise, the effect of the measured value decreases as the value of $\mathbf{Q}_{d}$ decreases. In order to simplify the procedure, it is assumed as the product of identity matrix and constant, $Q$. Therefore, if the Kalman gain increases, the proportion of the measured value $(z(k+1))$ increases. Similarly, if the Kalman gain decreases, the proportion of the predicted value $(\hat{\mathbf{x}}(k+1))$ increases. This relationship can be seen from the equation for calculating the estimated value in the correction stage. The algorithm with a recursive structure, as shown in Figure 3, summarizes the various stages of the Kalman filter, as described previously. 


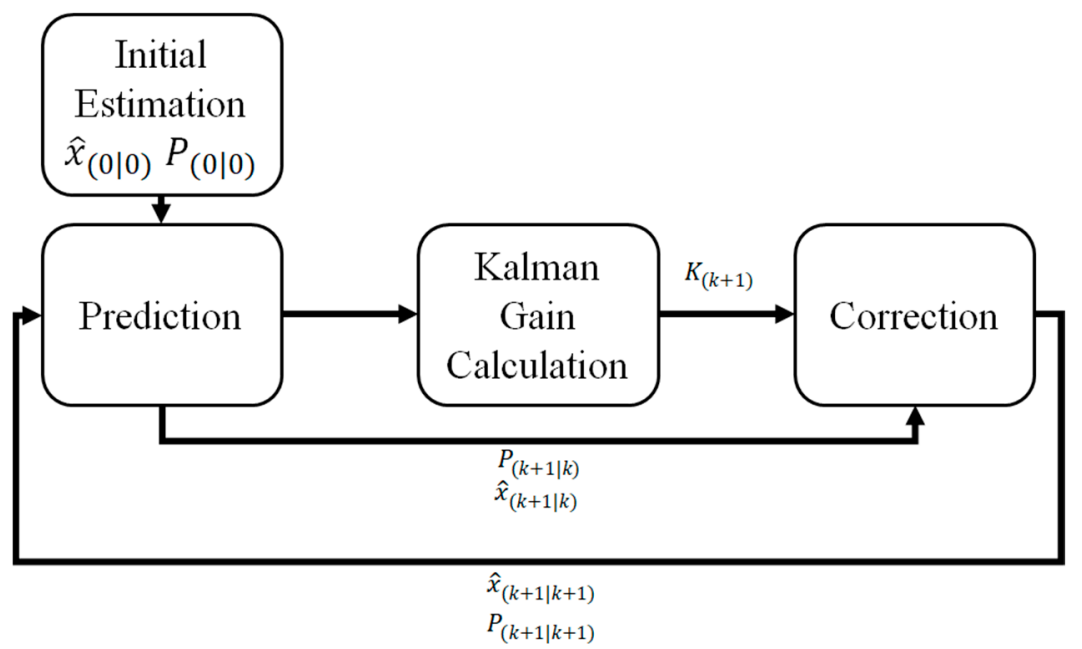

Figure 3. Recursive structure algorithm of the Kalman filter.

A simulation was performed using virtual, synthesized signals to verify the filtering performance of the Kalman filter. As shown in Figure 4a, the signal is in the shape of a sine wave between 0.001 and $0.004 \mathrm{~s}$. Beyond this period, the true signal has a value of zero. Signals other than the true signal include Gaussian noise and ripple voltage signals. Figure $4 \mathrm{~b}$ shows a signal in the shape of a triangular wave. This signal represents a combined signal of the ripple voltage signal and Gaussian noise. Combining the true signal with the Gaussian noise and the ripple voltage signal generates the signal shown in Figure 4c. This signal was assumed to be the measured signal. The Kalman filter described earlier was applied to the artificially synthesized and measured signal, and the result is shown in Figure $4 \mathrm{~d}$. The blue line denotes 0.1 as the value of $Q$, and the red line denotes $1.0 \times 10^{-5}$ as the value of $Q$. If the value of $Q$ increases, the predicted value of the error covariance increases. When the predicted value of the error covariance increases, the Kalman gain increases accordingly, this result reflects the measured value to a greater degree. Therefore, as the value of $Q$ decreases, only the values between 0.001 and $0.004 \mathrm{~s}$, which is the interval within which the true signal has non-zero values, decrease while the values in the other intervals do not change. Thus, it was verified that the error due to the ripple voltage signal is very significant. The Kalman filter assumes that the noise is Gaussian. However, the ripple voltage signal is periodic, not a Gaussian noise. This discrepancy adversely affects the performance of predicting the true signal [34].

To solve this problem, a small $Q$ value was used to minimize the Kalman gain. If the Kalman gain is decreased, the value of the system model becomes important to the resulting value of the Kalman filter. Moreover, it slows down the reflection of the measured value so that the ripple voltage signal can be derived appropriately. This effectively filters out the Gaussian noise, but the ripple voltage signal, which is a non-Gaussian noise, remains. Due to the signal being measured instantaneously having a very high frequency, it slows down the reflection of the estimated value. The ripple voltage signal extracted in this manner is subtracted from the raw signal to obtain the desired true signal. The value of $Q$ was determined via the trial-error method. In order to obtain a better noise canceling performance, the value was set as $1.0 \times 10^{-5}$ during repeated simulations. We denoted this algorithm as the Kalman filter-ripple voltage (KF-RV), and it is defined below:

$$
\begin{aligned}
& z(k+1)-\hat{\mathbf{x}}(k+1 \mid k+1)_{K F-R V} \\
& =z(k+1)-\hat{\mathbf{x}}(k+1 \mid k)+\mathbf{K}(k+1)[z(k+1)-\mathbf{H} \hat{\mathbf{x}}(k+1 \mid k)] \\
& =(1-\mathbf{K}(k+1)) z(k+1)+(1-\mathbf{K}(k+1) \mathbf{H}) \hat{\mathbf{x}}(k+1 \mid k)
\end{aligned}
$$

The result of applying this filter to the virtual signal is shown in Figure 5. The light blue line represents the true signal, and the red line represents the signal to which the proposed KF-RV is applied. The error rate can be calculated as $e_{r m s}$ and $e_{\max }$ [26]. These 
values are obtained by dividing the average of the difference between the measurement and the estimation by the root mean square (RMS) of the measurement and the maximum value of the measurement, respectively. The error rate for the virtual signal was calculated to verify the performance of the proposed algorithm. The results are shown in Table 1, and it was confirmed that the proposed algorithm has a much superior filtering effect on the ripple voltage signal than the classical Kalman filter.

$$
\begin{aligned}
& e_{r m s}=\frac{1}{X_{r, \text { meas }, \text { rms }}} \sum_{i=1}^{N} \frac{\left|X_{r, \text { meas }}(i)-X_{r, \text { est }}(i)\right|}{N} \\
& e_{\text {max }}=\frac{1}{X_{r, \text { meas }, \text { max }}} \sum_{i=1}^{N} \frac{\left|X_{r, \text { meas }}(i)-X_{r, \text { est }}(i)\right|}{N}
\end{aligned}
$$

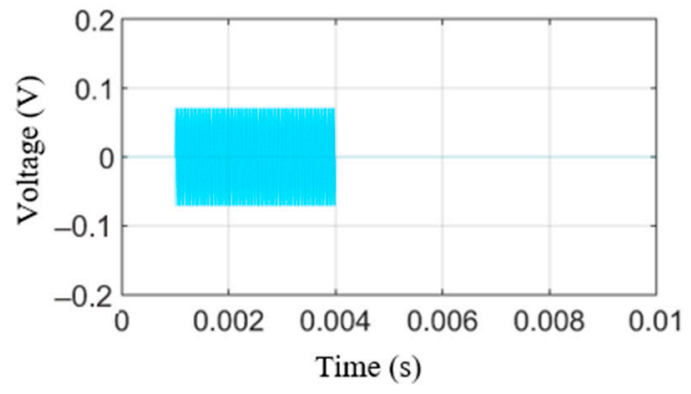

(a) True signal.

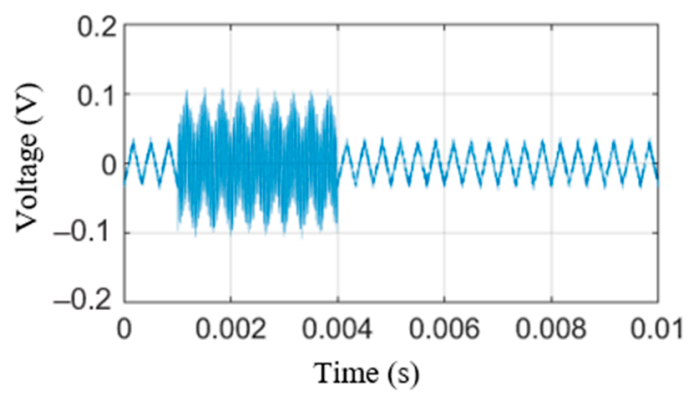

(c) Raw signal.

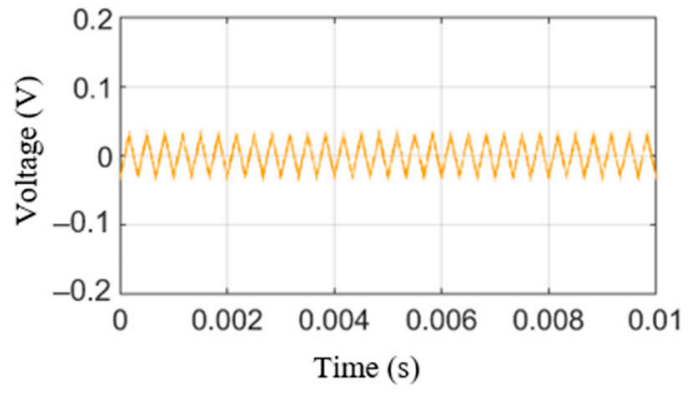

(b) Noise and ripple voltage signals.

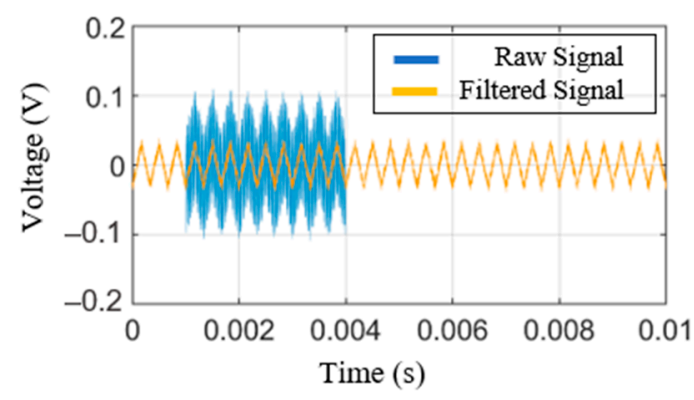

(d) Raw and filtered signals.

Figure 4. Simulation results of the classical Kalman filter.

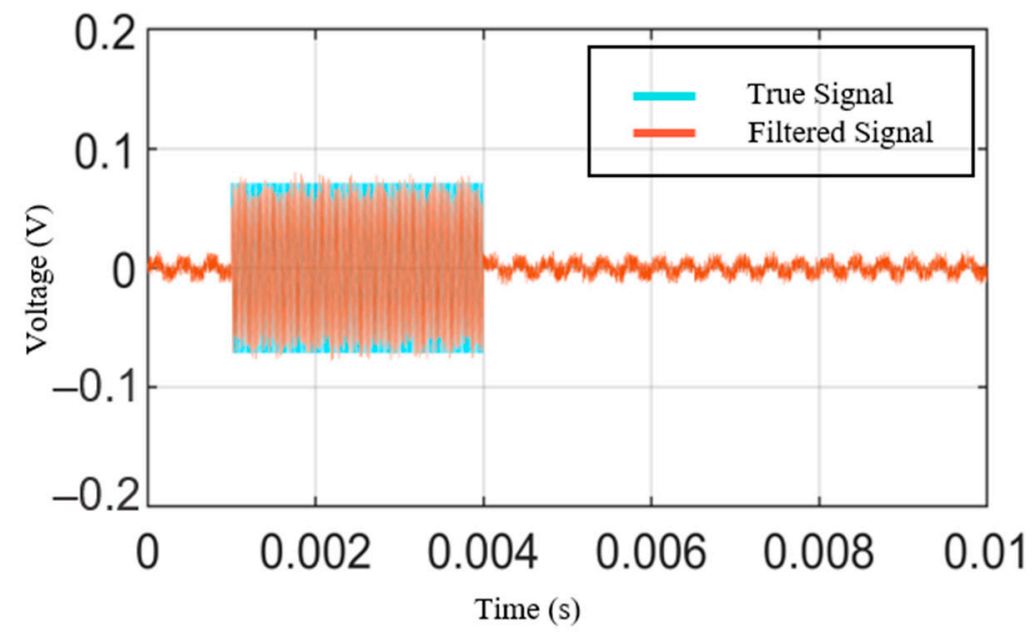

Figure 5. Simulation results of KF-RV. 
Table 1. Comparison of the estimation performances.

\begin{tabular}{ccc}
\hline & $\boldsymbol{e}_{\boldsymbol{r m s}} \mathbf{( \% )}$ & $\boldsymbol{e}_{\max } \mathbf{( \% )}$ \\
\hline Classical Kalman Filter with $\mathrm{Q}_{1}(0.1)$ & $62.60 \%$ & $25.49 \%$ \\
\hline Classical Kalman Filter with $\mathrm{Q}_{2}(0.00001)$ & $105.68 \%$ & $43.02 \%$ \\
\hline KF-RV (Proposed) & $34.53 \%$ & $14.06 \%$ \\
\hline
\end{tabular}

\section{Sheet Metal Forming Experiment}

The usefulness of this study was verified through the hole expansion test conducted during the sheet metal forming process. The press equipment used in the experiment is shown in Figure 6a. It consists of a pressure gauge, a press body, an indicator and a load cell and has a maximum load of $5000 \mathrm{~N}$ and a maximum stroke of $225 \mathrm{~mm}$. The hole expansion specimen, shown in Figure 6, is placed on a moving plate, and both ends of the specimen are fixed. While the moving plate of the press is lowered, the specimen undergoes plastic deformation, and the hole expands. When the moving plate reaches the bottom dead center, it stops. AE signals are collected over the whole stroke range, and results are analyzed. Figure $6 \mathrm{~b}, \mathrm{c}$ show, the schematic diagrams before and after the hole expansion test. The AE sensor could not be attached directly to the workpiece due to the characteristics of sheet metal forming. Therefore, this device was fabricated in such a way that the sensor could be attached to and detached from the upper moving plate that is closest to the workpiece. Moreover, the sensor was fixed to one side of the moving plate to ensure that it is not affected by the vibrations of the operating press. The test has been conducted in a semi-outdoor laboratory and indoor laboratory. The semi-outdoor and indoor laboratory temperatures are $18{ }^{\circ} \mathrm{C}$ and $20^{\circ} \mathrm{C}$, respectively. Furthermore, the humidity of semi-outdoor and indoor laboratory humidity is $40-60 \%$.

It is generally known that the main frequency range of fracture for low-carbon steel is from 60 to $500 \mathrm{kHz}$ [35]. In order to exactly analyze the frequency range of commercialquality hot-rolled steel (SPHC), the AE signal during the hole expansion test was measured and analyzed by using the AE sensor for the broadband frequency range. From the frequency analysis of preliminary test results, it is confirmed that the maximum peak frequency of the AE signal for SPHC is $60 \mathrm{kHz}$. Since resonant AE sensors have high sensitivity and narrow frequency bandwidth, the resonant type of AE sensor (Physical Acoustics Corp., West Windsor Township, NJ, USA, R6I-AST) is selected to detect AE signals with a low amplitude [36]. The specifications of the AE sensor are listed in Table 2. The peak sensitivity ( $\mathrm{V} / \mu \mathrm{bar}$ ) is $-23 \mathrm{~dB}$, and the operating frequency region is $40-100 \mathrm{kHz}$. The AE sensor used in the AE measurements is made of piezoelectric materials such as lead zirconate titanate (PbZrxTi1-XO3, PZT). It has been generally known that PZT can convert structural vibration energy into electrical energy. The AE signal is transferred from specimen to sensor, and then the deformation of PZT occurred, and the electrical energy is generated. As shown in Figure $6 \mathrm{~b}$, the AE sensor is mounted to the moving plate by using a magnetic holder. The magnetic holder is electrically isolated to the AE sensor. The triboelectric effect, which is a type of contact electrification between dissimilar materials, can make additional noise. In order to reduce the triboelectric noise, a double-shielded BNC cable is used to prevent the noise. Furthermore, any movements such as twisting or transient impact are restricted during the test. AE signals are converted to digital signals and transferred to each other via an $\mathrm{A} / \mathrm{D}, \mathrm{D} / \mathrm{A}$ board, and a data acquisition board (NI Corp., Austin, TX, USA, USB-6341). For more information on the data acquisition board, please refer to reference [37]. 


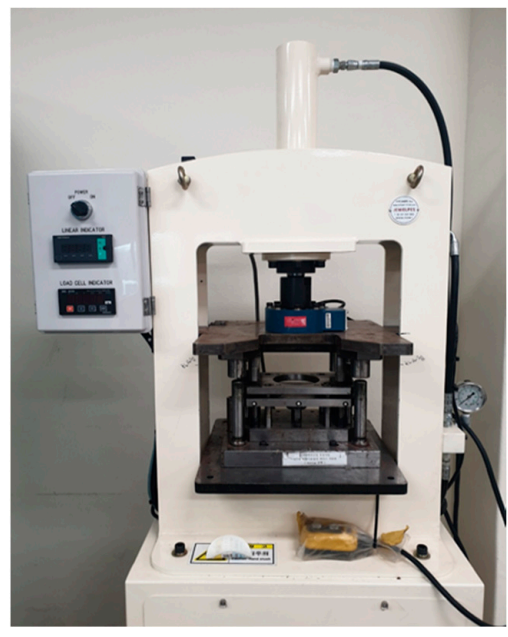

(a) Photograph.

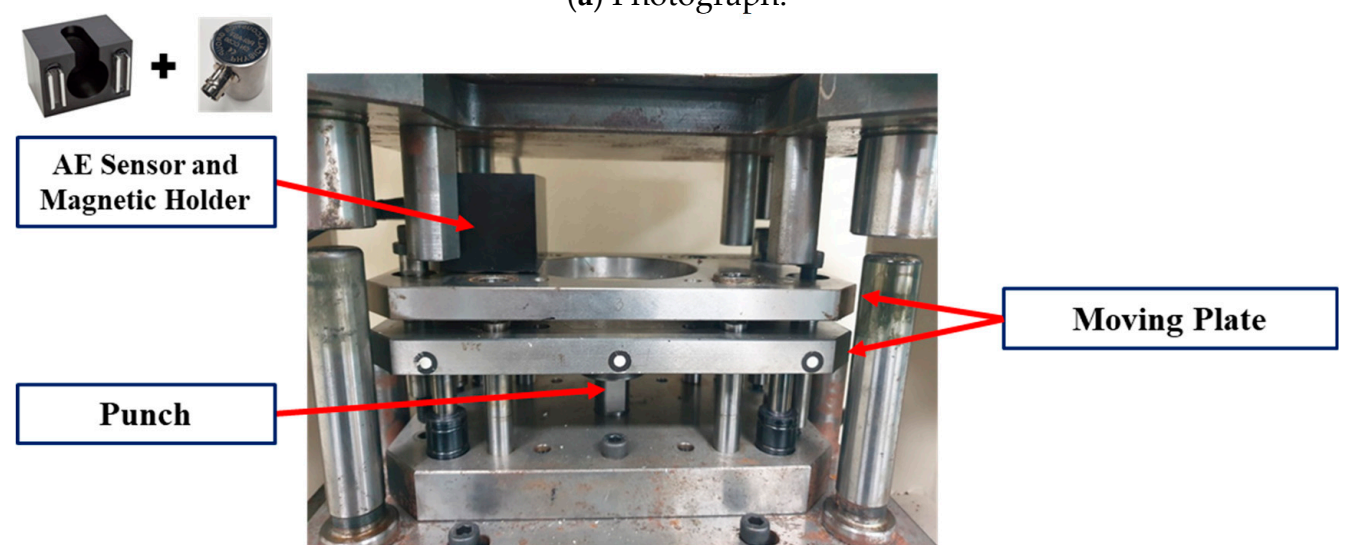

(b) Enlarged view of the press.

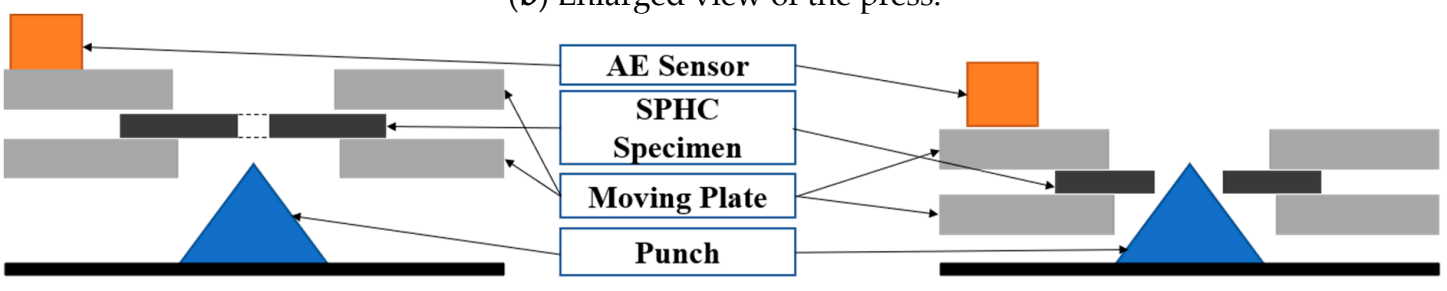

(c) Mechanism of press process.

Figure 6. Hole expansion test using AE sensor.

Table 2. R6I-AST specifications.

\begin{tabular}{|c|c|c|c|c|c|}
\hline \multicolumn{6}{|c|}{ Sensor Specifications } \\
\hline $\begin{array}{l}\text { Peak sensitivity, } \\
\text { Ref } V /(\mathrm{m} / \mathrm{s})\end{array}$ & $117 \mathrm{~dB}$ & Directionality & $+/-1.5 \mathrm{~dB}$ & $\begin{array}{l}\text { Output Drive } \\
\text { Impedance }\end{array}$ & $50 \Omega$ \\
\hline Peak Sensitivity, Ref V/ $\mu$ bar & $-23 \mathrm{~dB}$ & Gain & $40 \mathrm{~dB}$ & $\begin{array}{l}\text { Temperature } \\
\text { Range }\end{array}$ & -35 to $75^{\circ} \mathrm{C}$ \\
\hline Operation Frequency Range & $40-100 \mathrm{kHz}$ & $\begin{array}{c}\text { Power } \\
\text { Requirements }\end{array}$ & 20-30 VDC @ 25 mA & Shock Limit & $500 \mathrm{~g}$ \\
\hline $\begin{array}{l}\text { Resonant Frequency, } \\
\text { Ref } \mathrm{V} /(\mathrm{m} / \mathrm{s})\end{array}$ & $55 \mathrm{kHz}$ & Dynamic Range & $>87 \mathrm{~dB}$ & Dimensions & $29 \mathrm{~mm} \mathrm{OD} \times 40 \mathrm{~mm} \mathrm{H}$ \\
\hline $\begin{array}{l}\text { Resonant Frequency, } \\
\text { Ref } \mathrm{V} / \mu \mathrm{bar}\end{array}$ & $98 \mathrm{kHz}$ & $\begin{array}{l}\text { Noise Level } \\
\text { (RMS RTI) }\end{array}$ & $<3 \mu \mathrm{V}$ & Weight & $98 \mathrm{~g}$ \\
\hline Face Material & Ceramic & Connector & $\mathrm{BNC}$ & $\begin{array}{l}\text { Connector } \\
\text { Locations }\end{array}$ & Side \\
\hline
\end{tabular}


The die used in the experiment is used for the hole expansion test. As illustrated in Figure 6, the test specimen was lowered onto a punch, which has a shape pointed to the top and is fixed to the lower part, to expand the hole in the test specimen. The characteristics of the deformation changed according to the size of the hole and the thickness of the test specimen. In the case of a thin plate and a large hole, the hole expanded without fracture. However, when the hole size was relatively small, a fracture occurred while the hole was expanding. The test specimen used was SPHC, and the thickness of the plate was $2 \mathrm{~mm}$. The modulus of elasticity was $210 \mathrm{MPa}$, the yield stress was $257 \mathrm{MPa}$, and the tensile strength was $270 \mathrm{MPa}$. Furthermore, SPHC that has an elongation of $31 \%$ is a classic ductile material. The SPHC test specimens had a thickness of $2 \mathrm{~mm}$ before the hole expansion test, and the test was conducted using the test specimens with a $4 \mathrm{~mm}$ hole drilled in the center. Four identical test specimens were prepared, and the test was performed two times at different sites. The same press equipment was used for all four test specimens. Tests \#1 and \#2 were conducted in a laboratory exposed to the outside environment, whereas tests \#3 and \#4 were conducted in a laboratory environment.

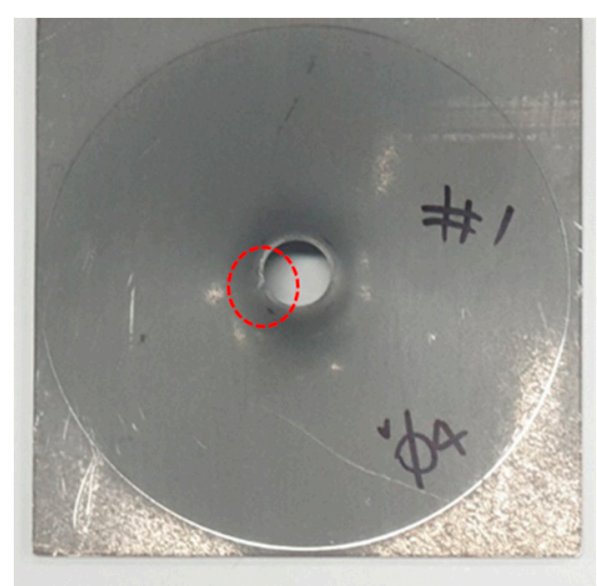

(a) Semi-outdoor lab (\#1).

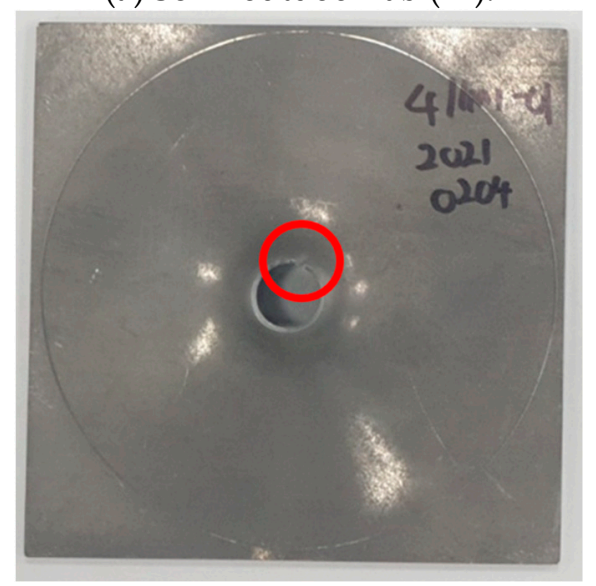

(c) Indoor lab (\#3).

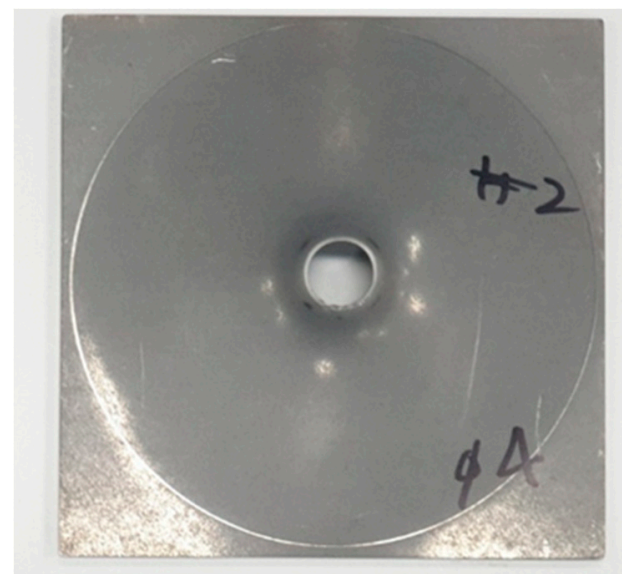

(b) Semi-outdoor lab (\#2).

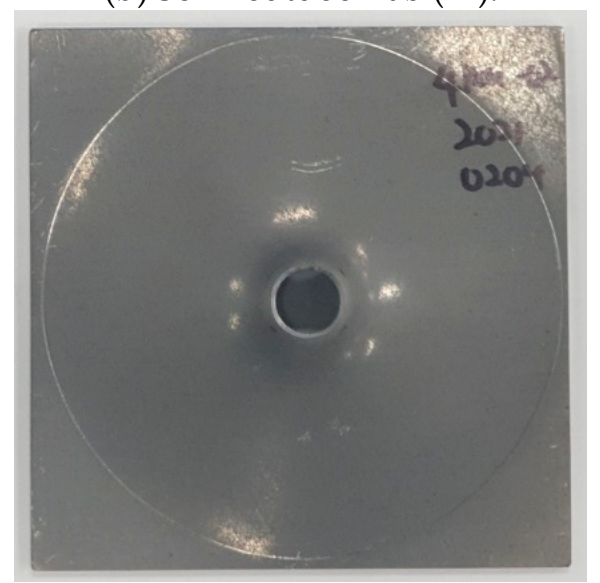

(d) Indoor lab (\#4)

Figure 7. Images of test specimens after the hole expansion test.

Figure 7 shows the test specimens after the hole expansion test; the test specimens have holes of the same size. In Figure 7b,d, plastic deformation occurred, in which only the size of the hole was expanded. However, when the diameter of the hole became much larger than the initial diameter, a fracture occurred, as indicated by the red circle in Figure $7 \mathrm{a}, \mathrm{c}$. The deformation type of the specimen is determined according to yield strain, ultimate tensile strength, necking strain, and fracture strain. The strain values are measured by DIC (Digital Image Correlation). For more details of strain measurement, please refer to 
our previous study [38]. The difference is caused by various factors, such as minuscule differences in the thickness of the test specimens, as well as the hole-processing precision and alignment. This study was conducted to distinguish the occurrence of fracture in the test specimens due to these causes using the AE.

During the pressing process, the pre-amplifier receives the AE signal generated from the workpiece. The pre-amplifier then amplifies the signal and transmits it to the measuring device. Figure 8 shows the circuit diagram of the AE sensor and the DAQ device [39]. As shown in the circuit diagram, a power supply that can provide a voltage less than or equal to $28 \mathrm{~V}$ and a current less than or equal to $100 \mathrm{~mA}$ and a separate current limiting circuit are needed for the AE sensor to operate properly.

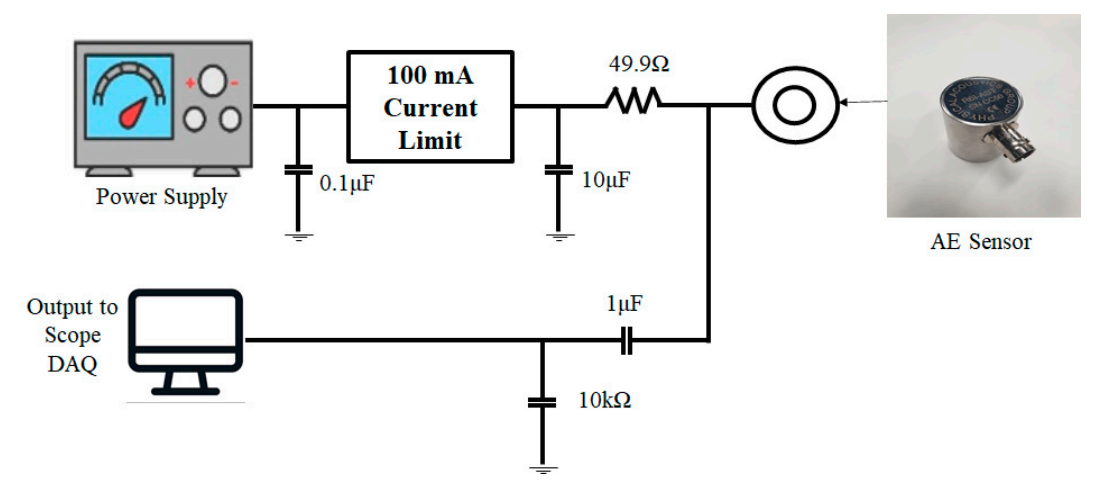

Figure 8. Driving circuit for AE sensor.

The AE signal is generated in a very short time. However, because the sampling time is also very short, the data volume is vast. Hence, an appropriate threshold voltage is set for a typically processed signal, as described in the introduction. It is common to analyze the aforementioned AE parameters based on the threshold voltage [10-24].

Figure 9 illustrates the measurement results when the press is in a non-operative state during the hole expansion test. However, because the press was not operating, only the noise and ripple voltage signals were measured. Figure 9 a shows the measured results without power supply input. The value is zero, but the measured results with power supply input are not zero, as shown in Figure 9b,c. The peak-to-peak values of the semi-outdoor lab and indoor labs are $0.1010 \mathrm{~V}$ and $0.0493 \mathrm{~V}$, respectively. In other words, the maximum values are 0.0506 and $0.0246 \mathrm{~V}$, respectively; the minimum values are -0.0504 and $-0.0247 \mathrm{~V}$, respectively. From Figure 9, the ripple voltage signal is a result of the power supply. The signals are repeatedly measured three times, and the peak amplitudes of the signal are almost the same.

Figure 10 shows the raw AE signals for testing materials in the time domain. The signals, as shown in Figure 10a,b, were obtained in a laboratory exposed to the outside environment, and the signals shown in Figure 10c,d were obtained in a laboratory environment. From these figures, it can be seen that the generated AE signal is not much larger than the noise and ripple voltage signals, as illustrated in Figure 9. The positive threshold voltage was set to $0.07 \mathrm{~V}$ based on the measured results to derive the aforementioned AE parameters. Here, $0.07 \mathrm{~V}$ is slightly larger than the noise level. Based on this value, previously described AE parameters were obtained, and the results are shown in Table 3. As can be seen from the results, it was difficult to uncover the correlation between the presence or absence of a fracture and the parameters, such as ring-down count, duration time, and peak amplitude. First, the ring-down counts for \#3 and \#4 were similar, but the presence or absence of a fracture for \#3 and \#4 was different. Moreover, the peak amplitudes were similar for \#1 and \#4 and \#2 and \#3. However, the presence or absence of a fracture was again different. Lastly, \#2 and \#1 had the longest and shortest duration time, respectively. Moreover, no fractures were observed in either \#2 or \#4. Furthermore, because the threshold voltage was set high due to a large ripple voltage signal, we determined that 
it was difficult to analyze the correlation between the presence or absence of a fracture and the parameters.

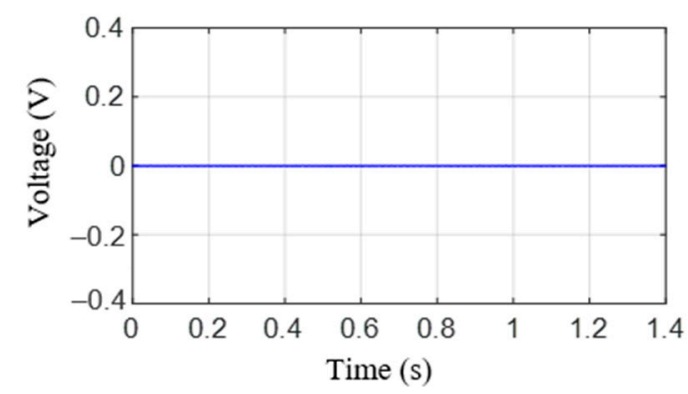

(a) W/o Power Supply.

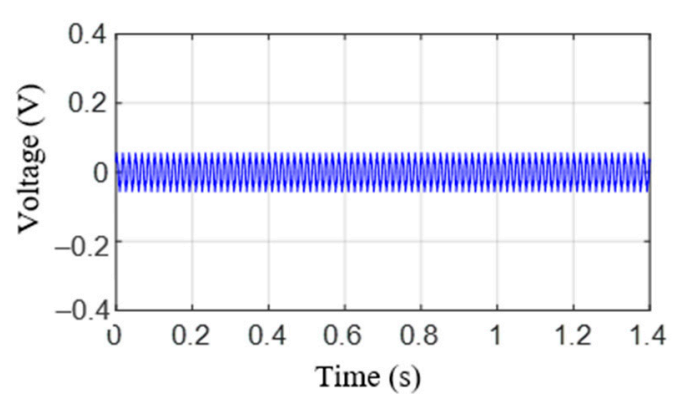

(b) W/ Power Supply in Semi-Outdoor Lab.

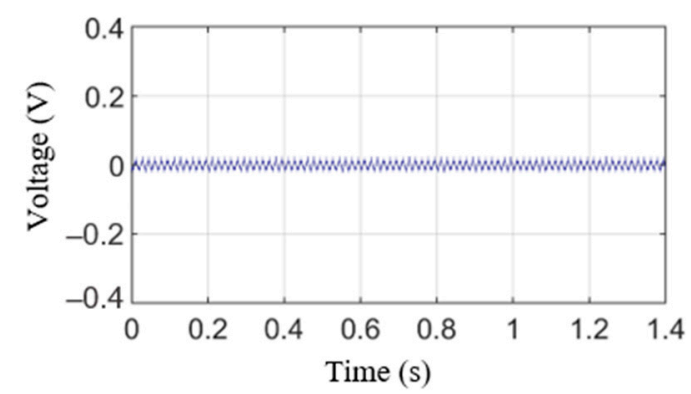

(c) W/ Power Supply n Indoor Lab.

Figure 9. AE raw signal without press process.

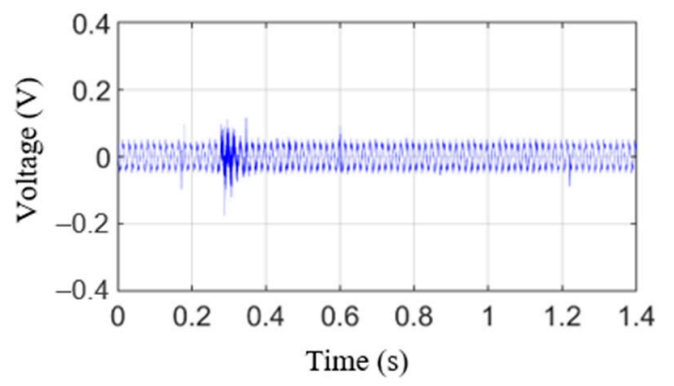

(a) Semi-outdoor lab (\#1).

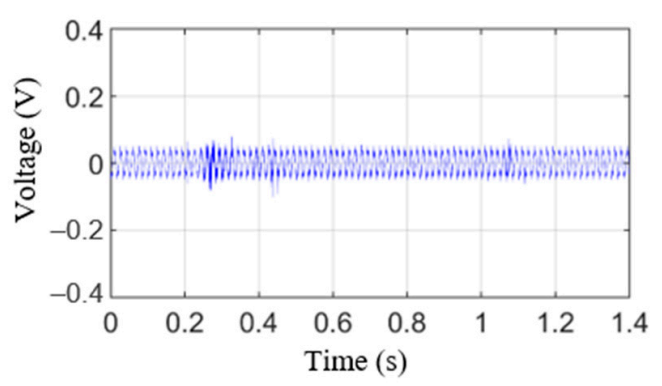

(b) Semi-outdoor lab (\#2).

Figure 10. Cont. 


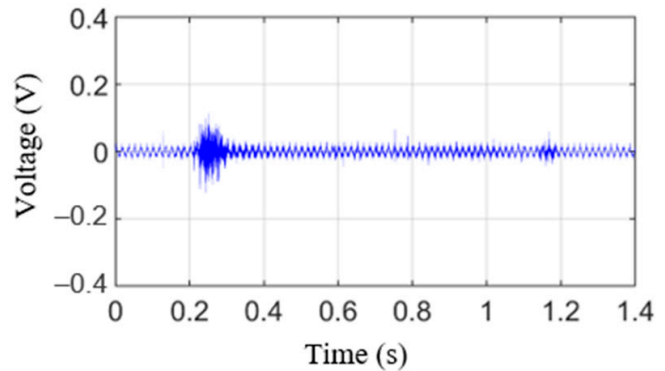

(c) Indoor lab (\#3).

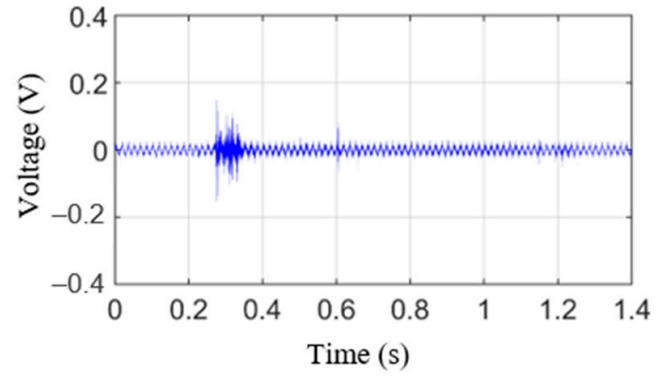

(d) Indoor lab (\#4).

Figure 10. AE raw signal with press process.

Table 3. AE parameters from the raw signal.

\begin{tabular}{cccccc}
\hline & Ring-Down Count & Duration Time & Peak Amplitude & $\begin{array}{c}\text { Mean Frequency } \\
\text { (Standard Deviation) }\end{array}$ & Deformation Type \\
\cline { 2 - 5 } & Unit: EA & Unit: s & Unit: V & Unit: kHz & \\
\hline$\# 1$ & 152 & 0.0349 & 0.1749 & $7.88( \pm 19.17)$ & Plastic deformation and fracture \\
\hline$\# 2$ & 11 & 0.184 & 0.1006 & $5.16( \pm 17.3)$ & Plastic deformation \\
\hline$\# 3$ & 23 & 0.0498 & 0.1139 & $0.652( \pm 6.54)$ & Plastic deformation and fracture \\
\hline$\# 4$ & 21 & 0.072 & 0.1474 & $0.35( \pm 4.32)$ & Plastic deformation \\
\hline
\end{tabular}

Fast Fourier transform (FFT) is applied to the raw signals of testing materials. Figure 11 shows raw AE signal characteristics in the frequency domain. Similar to Figure 9, the signals shown in Figure 10a,b were obtained in a laboratory exposed to the outside environment, and the signals shown in Figure 10c,d were obtained in a laboratory environment. From these figures, the peak frequencies of $\mathrm{AE}$ signals in the semi-outdoor labs and indoor labs are 60.3 and $31 \mathrm{kHz}$, respectively. Short-time Fourier transform (STFT), which is a sequence of Fourier transform of a windowed signal, is applied to the raw signals of the AE sensor [40]. STFT can be visualized by spectrogram. It shows the time-localized frequency information. Similar to Figure 10, the signals shown in Figure 12a-c were obtained in a laboratory exposed to the outside environment, and the signals shown in Figure $12 \mathrm{~d}-\mathrm{f}$ were obtained in a laboratory environment. The results in Figure 12a, $d$ are measured without a specimen during the press process. The vertical and horizontal axes represent frequency and time, respectively. The amplitude of a particular frequency at a particular time is represented by the color of each point in the spectrogram. From the comparison of the results with and without a specimen, the specimen and punch meet at period A (approximately $0.25-0.3 \mathrm{~s}$ ), and the hole in the specimen expands. Furthermore, the press process ends at period B (approximately 1.1-1.2 s). Due to friction between the punch and specimen, periods $A$ and $B$ show the signal with a wide spectrum ( $0-2$ and $40-200 \mathrm{kHz})$. Between periods A and B (approximately 0.3-1.1 s), the ripple voltage, noise, and AE signal are measured.

From the frequency analysis of the measured results in Figures 9 and 12, it is known that the peak frequencies of ripple voltage and noise are under $2 \mathrm{kHz}$; the peak frequencies of $\mathrm{AE}$ signal are near $40-60 \mathrm{kHz}$, and the magnitudes of ripple voltage and noise are higher than that of the AE signal. Furthermore, the amplitude of the AE signal with a fracture in Figure 12b,e is a little bit larger than that of the AE signal without fracture in Figure 12c,f. Furthermore, the mean frequency (MNF) of the measured results is obtained by the following equation

$$
M N F=\sum_{i=1}^{n} f_{i} P_{i} / \sum_{i=1}^{n} P_{i}
$$


where $f_{i}$ is frequency value at the frequency bin $i, P_{i}$ is the power spectrum at the frequency bin $i$, and $n$ is the length of frequency bin $i$. The mean frequency, which is calculated as the sum of the power spectrum and the frequency divided by the total sum of the power spectrum [41], and standard deviation are also shown in Table 3. As the small amplitude AE signals are not resolved from background noise and ripple voltage, the value of obtained mean frequencies is also small, and its standard deviations are very big.

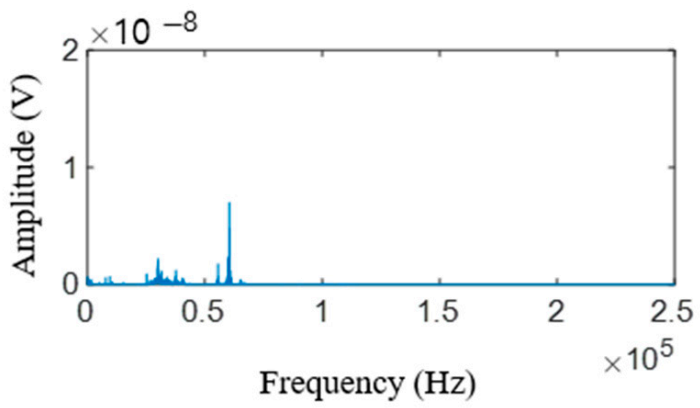

(a) Semi-outdoor lab (\#1).

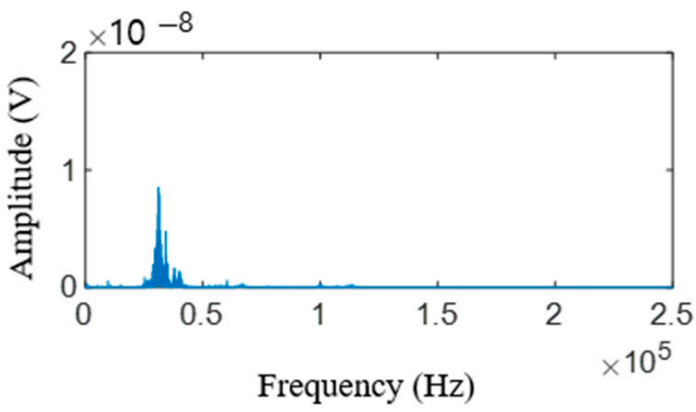

(c) Indoor lab (\#3).

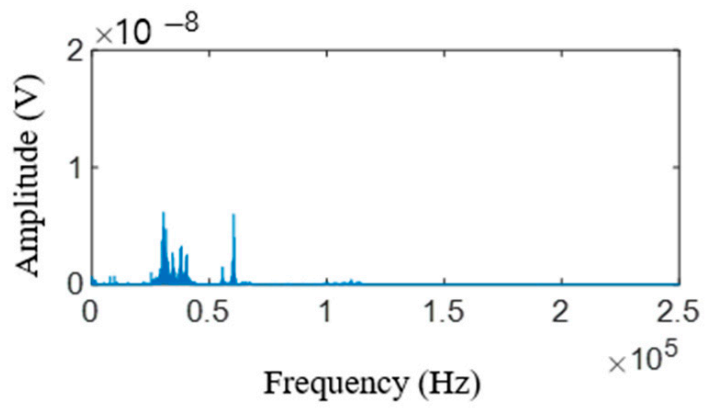

(b) Semi-outdoor lab (\#2).

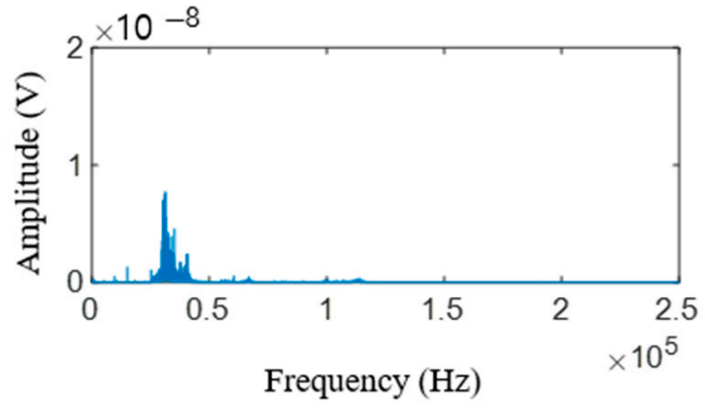

(d) Indoor lab (\#4).

Figure 11. Result of fast Fourier transform applied to AE filtered signal.

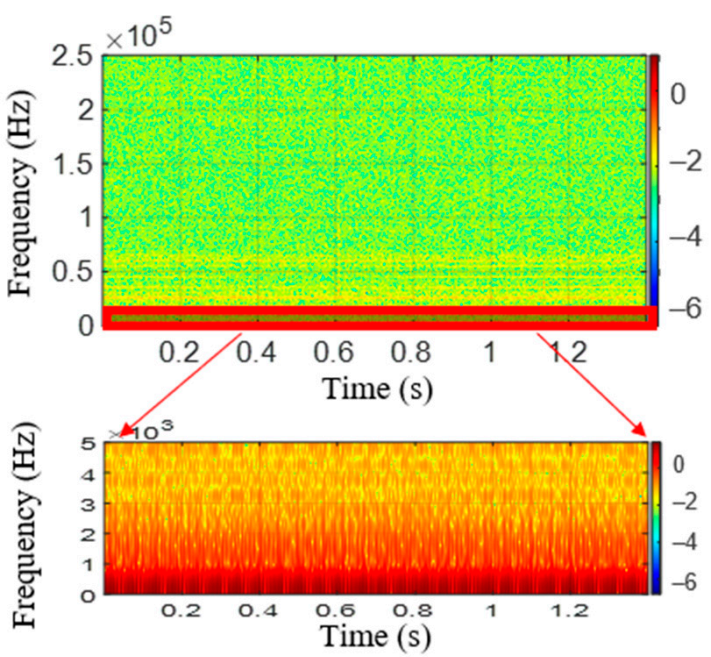

(a) No specimen in Semi-outdoor lab.

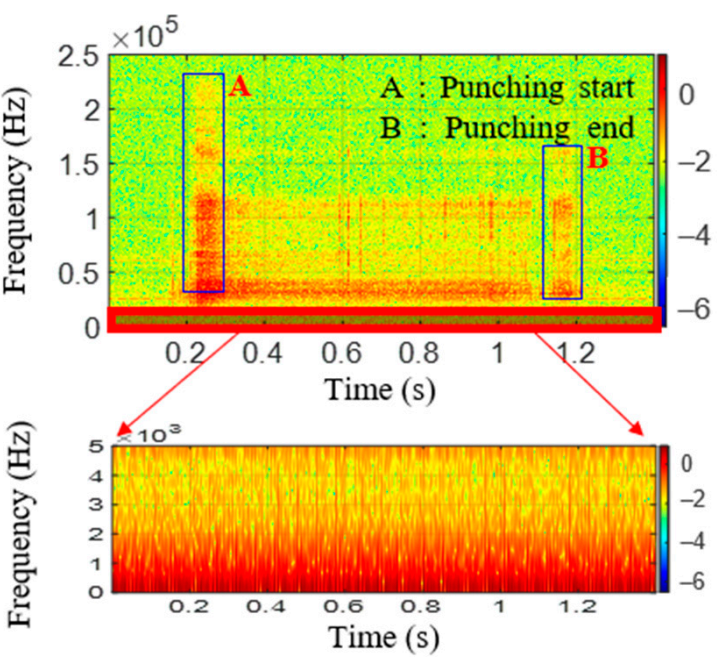

(b) Semi-outdoor lab (\#1).

Figure 12. Cont. 


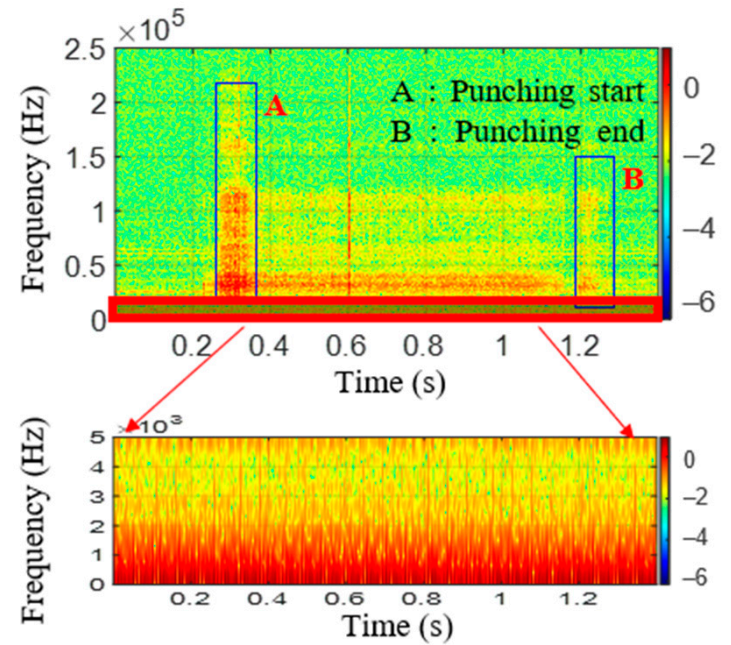

(c) Semi-outdoor lab (\#2).

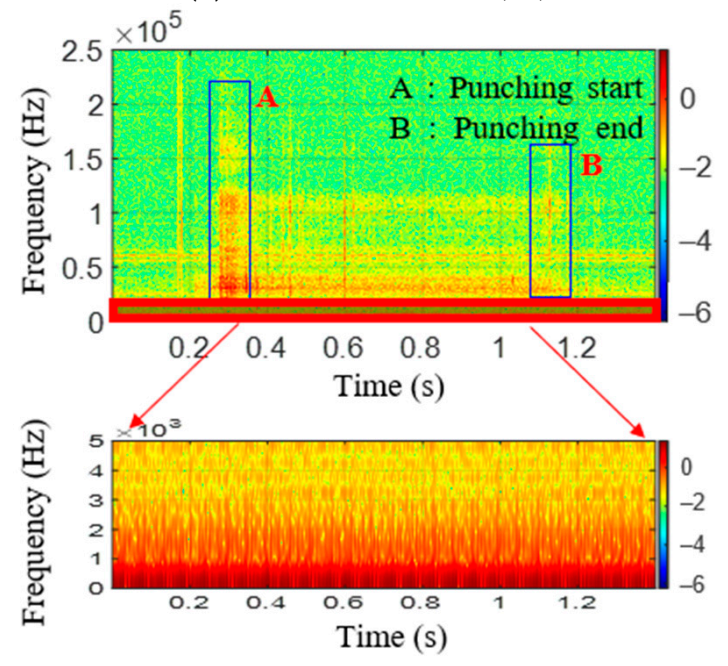

(e) Indoor lab (\#3).

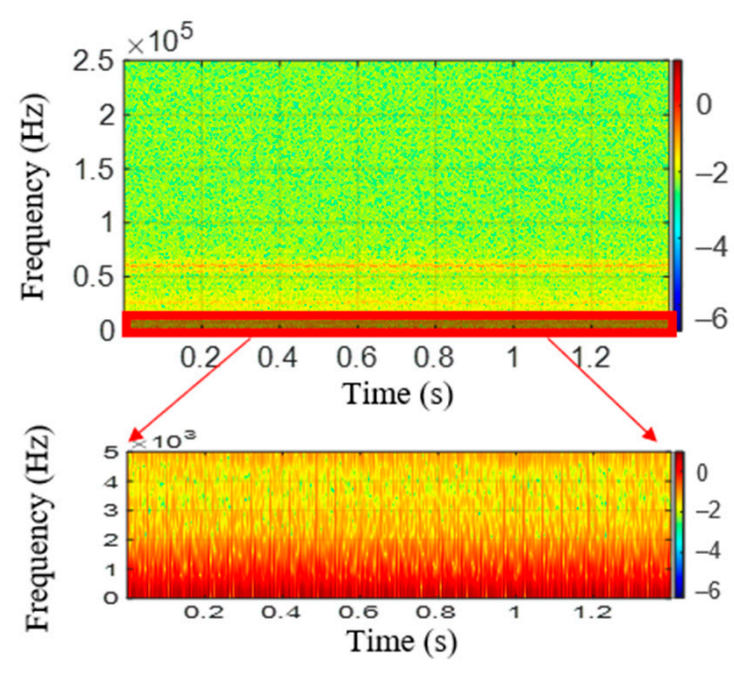

(d) No specimen in indoor lab.

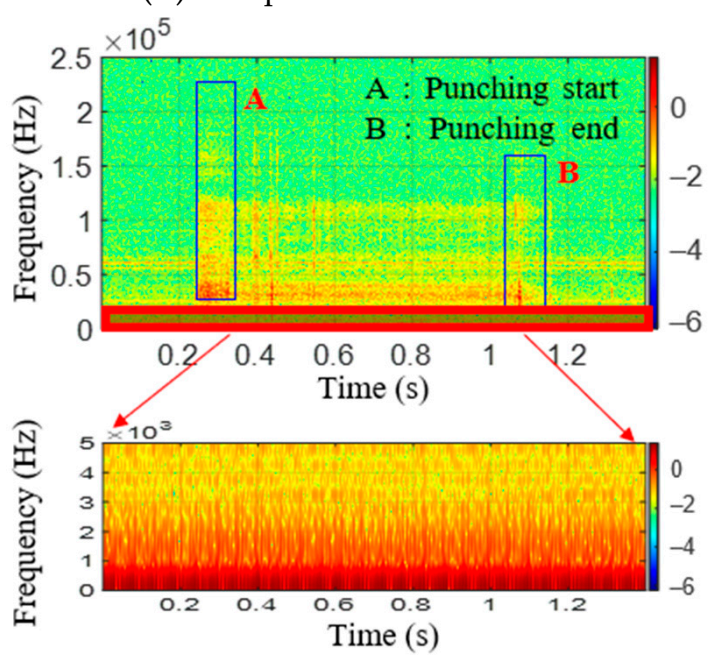

(f) Indoor lab (\#4).

Figure 12. Spectrogram of AE raw data with press process.

\section{AE Detection Method and Discussions}

As mentioned earlier, the $\mathrm{AE}$ signals at factories where the press operations are performed have a very high signal-to-noise ratio. Therefore, it is very difficult to detect and analyze the AE signals. To detect the $\mathrm{AE}$ signals when there were many noises and ripple voltage signals, the KF-RV algorithm was applied to the data from Figure 9, and the results are plotted in Figure 13. By applying the filter to the ripple voltage signal and noise signal in the semi-outdoor lab and indoor lab, the ripple voltage signal and noise signal were averagely reduced by $98.1 \%$. Based on these results, it was found that the proposed KF-RV algorithm effectively attenuates the ripple voltage signal and noise signal.

Figure 14 shows the results of applying the KF-RV algorithm to the raw AE signal generated during the press operation. Because the noise and ripple voltage signals have been removed, only the pure AE signal can be seen. In Figure 14a-d, it can be seen that plastic deformation and fractures occurred between 0.2 and $0.4 \mathrm{~s}$ primarily due to the press operation. However, it is difficult to determine if a fracture occurred based only on the shape of the graph. Hence, the AE activity was analyzed. As before, the threshold voltage was set, but it was set to $0.035 \mathrm{~V}$, which is half of $0.07 \mathrm{~V}$. Furthermore, the STFT of the filtered results were obtained and plotted in Figure 15. Since there are no signals at a low frequency in Figure 15, it can be confirmed that the noise and ripple voltage signals have been effectively removed. The parameters used in the experiment and the results are 
shown in Table 4. As shown in Table 4, the test specimens with fractures were identified using the number of ring-down counts. Signals \#1 and \#3 showed a large number of ring-down counts. When only plastic deformation occurred, which simply expanded the diameter of the hole, AE signals were present, but the number of ring-down counts was low. Furthermore, it can be observed that the mean frequencies of the filtered signals are bigger than that of the raw signal. By removing the noise and ripple voltage signals, the mean frequency of the filtered signal is in the frequency range of the AE event in Table 2. It was determined that this result was obtained because only meaningful AE signals were extracted by setting an appropriate threshold voltage instead of a high threshold voltage due to the ripple voltage signal.

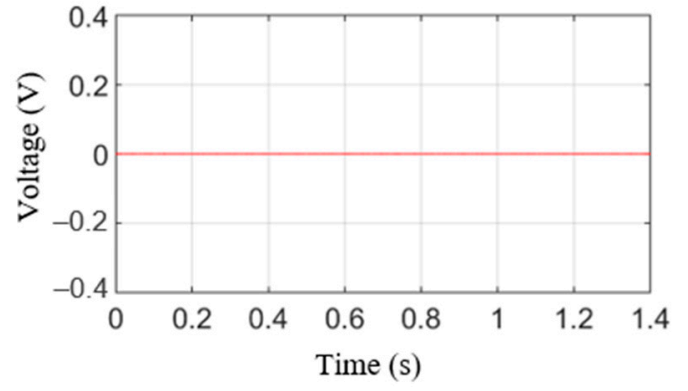

(a) W/ power supply in the semi-outdoor lab.

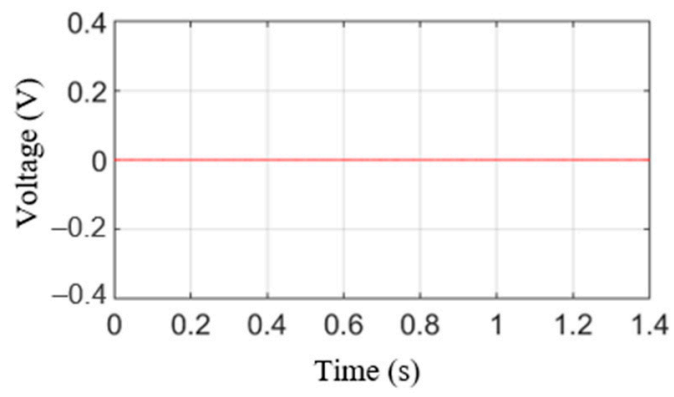

(b) W/ power supply in the indoor lab.

Figure 13. AE filtered signal without press process.

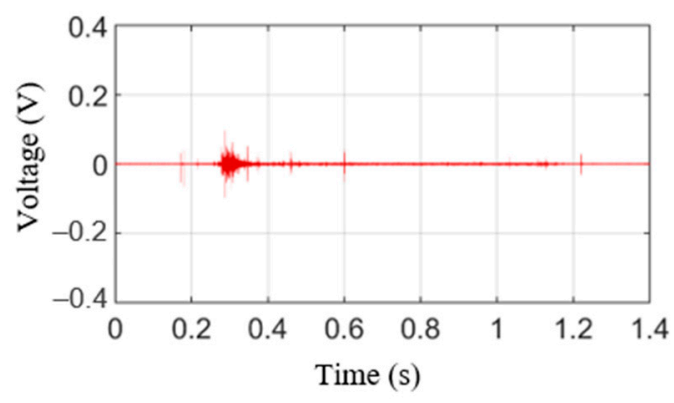

(a) Semi-outdoor lab (\#1).

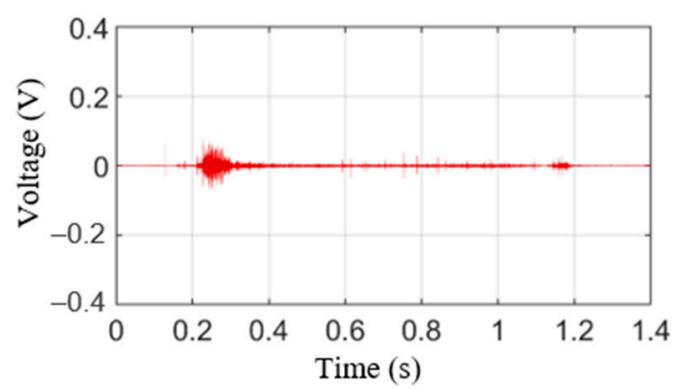

(c) Indoor lab (\#3).

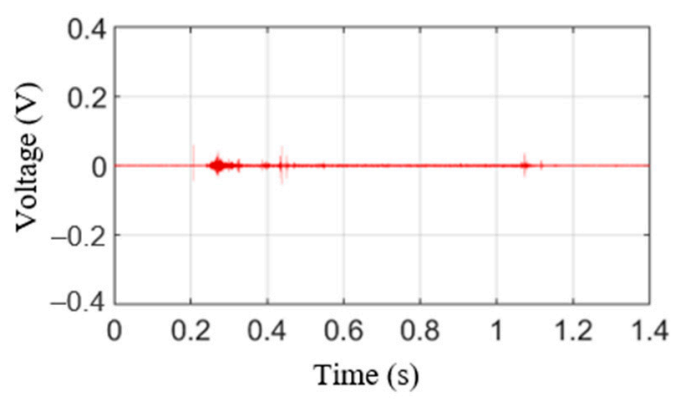

(b) Semi-outdoor lab (\#2).

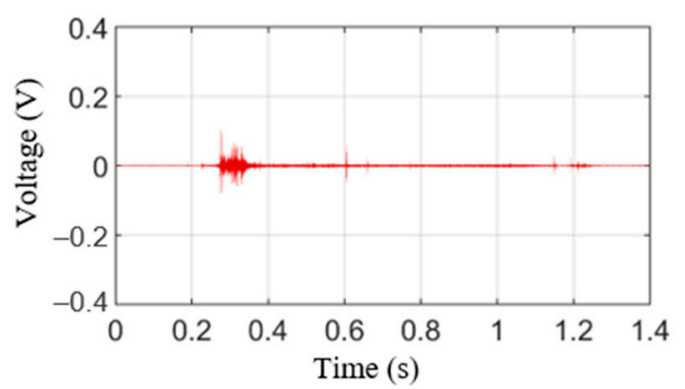

(d) Indoor lab (\#4).

Figure 14. AE filtered signal with press process. 


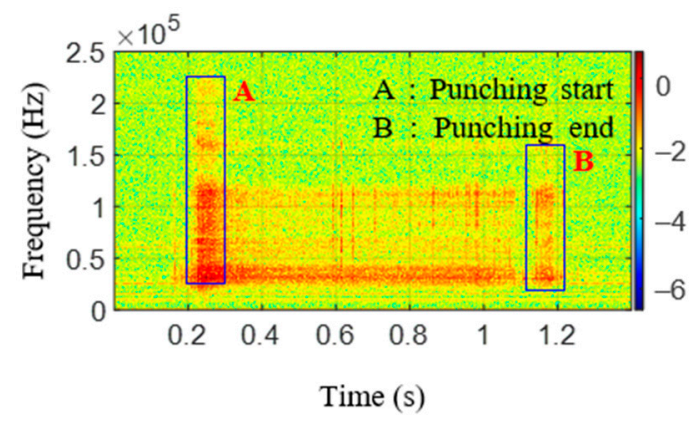

(a) Semi-outdoor lab (\#1).

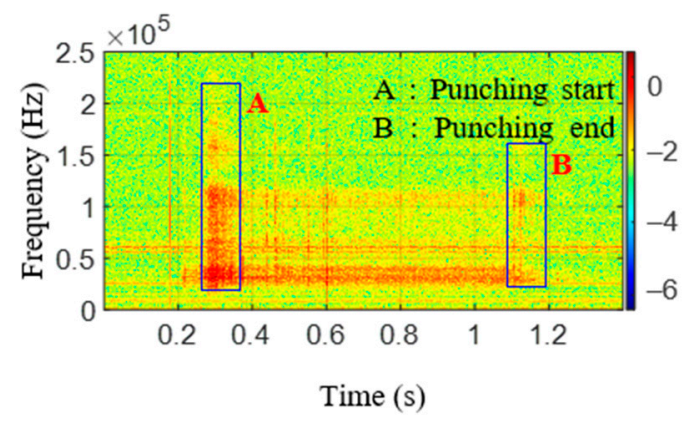

(c) Indoor lab (\#3).

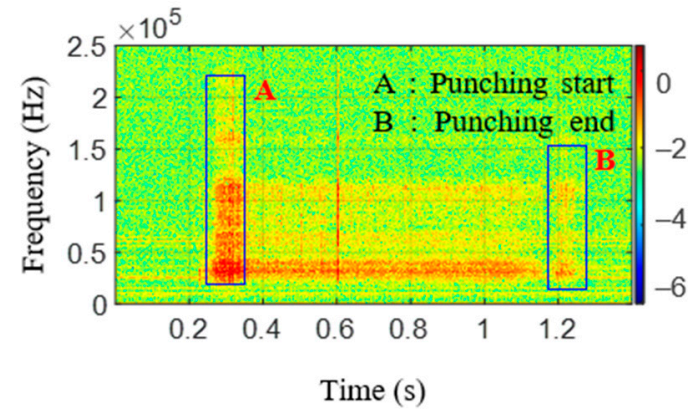

(b) Semi-outdoor lab (\#2).

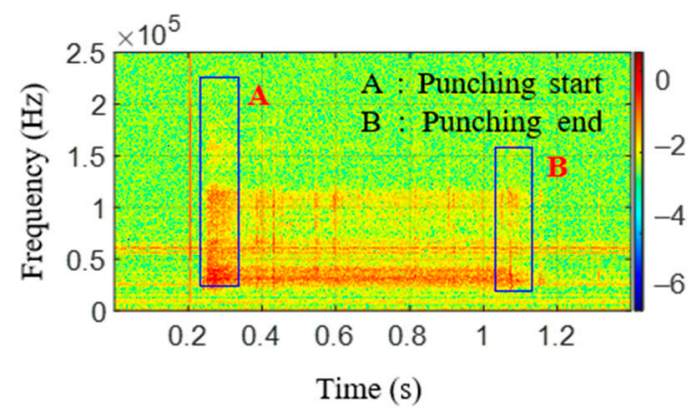

(d) Indoor lab (\#4).

Figure 15. Result of STFT using AE filtered data.

Table 4. AE parameters from filtered data.

\begin{tabular}{cccccc}
\hline & Ring-Down Count & Duration Time & Peak Amplitude & $\begin{array}{c}\text { Mean Frequency } \\
\text { (Standard Deviation) }\end{array}$ & Deformation Type \\
\cline { 2 - 5 } & Unit: EA & Unit: s & Unit: V & Unit: kHz & \\
\hline$\# 1$ & 132 & 0.03097 & 0.0967 & $43.1( \pm 25.4)$ & Plastic deformation and fracture \\
\hline$\# 2$ & 16 & 0.01892 & 0.0602 & $42.3( \pm 24.4)$ & Plastic deformation \\
\hline$\# 3$ & 147 & 0.051 & 0.0757 & $44.3( \pm 25.9)$ & Plastic deformation and fracture \\
\hline$\# 4$ & 69 & 0.05493 & 0.1038 & $45.4( \pm 27.6)$ & Plastic deformation \\
\hline
\end{tabular}

Thus, the AE signal is generated due to plastic deformation and fracture in sheet metal forming. If the noise and ripple voltage signals can be filtered out appropriately, the occurrence of fracture can be determined by deriving the ring-down count. Based on this outcome, this study confirmed that it is possible to determine the accurate time at which a defect occurs in the product during the sheet metal forming process.

\section{Conclusions}

In this study, an $\mathrm{AE}$ sensor was applied to predict fractures in ductile materials during the sheet metal forming process. Since the AE signal occurs when plastic deformation and fracture of metallic materials occur, the defect of the specimen can be detected in advance. However, the AE signals for ductile materials have a very high signal-to-noise ratio; hence, it is difficult to detect and analyze the AE signals of the ductile materials. So, a Kalman filter with a low Kalman gain was designed to extract only the ripple voltage and noise signal. Subsequently, the AE signal was obtained by subtracting the ripple voltage signal from the original raw signal. In order to confirm the performance of the proposed algorithm, a computer simulation has been conducted, and superior canceling performance was confirmed. By using the KF-RV algorithm, the activity of the extracted AE signal was analyzed using the ring-down count among various $\mathrm{AE}$ parameters to determine if there was a fracture in the test specimen. The sheet metal forming test was prepared to evaluate 
the performance of the proposed detection method. If ripple voltage and noise signals other than the AE signal are filtered out appropriately, the presence or absence of a fracture can be determined using the ring-down count parameter. Based on the test result, this study confirmed that it is possible to determine the accurate time at which a defect occurs in the product during the sheet metal forming process.

Author Contributions: Conceptualization, S.H.; validation, S.-M.J.; investigation, S.-M.J.; writingoriginal draft preparation, S.-M.J.; writing-review and editing, J.-S.O.; supervision, J.-S.O. All authors have read and agreed to the published version of the manuscript.

Funding: This work was supported by the National Research Foundation of Korea (NRF) and grant funded by the Korean government (MSIT) (No. 2020R1F1A1076435).

Institutional Review Board Statement: Not applicable.

Informed Consent Statement: Not applicable.

Conflicts of Interest: The authors declare no conflict of interest.

\section{References}

1. Kim, D.H.; Lee, W.K.; Kim, S.W. Analysis of Acoustic Emission Signal for the Detection of Defective Manufactures in Press Process. World Acad. Sci. Eng. Technol. 2009, 53, 1301-1305.

2. Kim, D.H.; Lee, W.K. A Judgment Algorithm of the Acoustic Signal for the Automatic Defective Manufactures Detection in Press Process. J. Korean Soc. Manuf. Process. Eng. 2010, 9, 76-82.

3. Kim, D.H.; Park, S.M.; Lee, W.K. Analysis of Various Acoustic Emission Signal for the Automatic Detection of Defective Manufactures in Press Process. J. Korean Soc. Manuf. Process Eng. 2010, 9, $14-25$.

4. Scruby, C.B. An introduction to acoustic emission. J. Phys. E Sci. Instrum. 1987, 20, 946-953. [CrossRef]

5. Abbasi, A.R.; Rafsanjani, A.; Farshidianfar, A.; Irani, N. Rolling element bearings multi-fault classification based on the wavelet denoising and support vector machine. Mech. Syst. Signal Process. 2007, 21, 2933-2945. [CrossRef]

6. Esmaeili, K.; Zuercher, M.; Wang, L.; Harvey, T.J.; Holweger, W. Advanced Signal Processing Techniques for Wind Turbine Gearbox Bearing Failure Detection; British Institute of Non-Destructive Testing: Northampton, UK, 2017.

7. Gholizadeh, S.; Leman, Z.; Baharudin, B. A review of the application of acoustic emission technique in engineering. Struct. Eng. Mech. 2015, 54, 1075-1095. [CrossRef]

8. Ahn, B.; Kim, J.; Choi, B. Artificial intelligence-based machine learning considering flow and temperature of the pipeline for leak early detection using acoustic emission. Eng. Fract. Mech. 2019, 210, 381-392. [CrossRef]

9. See, C.H.; Horoshenkov, K.V.; Bin Ali, M.T.; Tait, S.J. An Acoustic Sensor for Combined Sewer Overflow (CSO) Screen Condition Monitoring in a Drainage Infrastructure. Sensors 2021, 21, 404. [CrossRef]

10. Lyasota, I.; Kozub, B.; Gawlik, J. Identification of the tensile damage of degraded carbon steel and ferritic alloy-steel by acoustic emission with in situ microscopic investigations. Arch. Civ. Mech. Eng. 2019, 19, 274-285. [CrossRef]

11. Lee, J.K.; Lee, J.H.; Lee, S.P.; Son, I.S.; Bae, D.S. Acoustic emission and ultrasonic wave characteristics in TIG-welded 316 stainless steel. Met. Mater. Int. 2014, 20, 483-488. [CrossRef]

12. Stewart, F.R.; Qiu, Y.; Lay, H.S.; Newton, I.P.; Cox, B.F.; Al-Rawhani, M.A.; Beeley, J.; Liu, Y.; Huang, Z.; Cumming, D.R.S.; et al. Acoustic Sensing and Ultrasonic Drug Delivery in Multimodal Theranostic Capsule Endoscopy. Sensors 2017, 17, 1553. [CrossRef]

13. Alonso-Martín, F.; Gamboa-Montero, J.J.; Castillo, J.C.; Castro-González, Á.; Salichs, M. Ángel Detecting and Classifying Human Touches in a Social Robot Through Acoustic Sensing and Machine Learning. Sensors 2017, 17, 1138. [CrossRef] [PubMed]

14. Gao, X.-X.; Cui, J.-M.; Ai, M.-Z.; Huang, Y.-F.; Li, C.-F.; Guo, G.-C. An Acoustic Sensor Based on Active Fiber Fabry-Pérot Microcavities. Sensors 2020, 20, 5760. [CrossRef] [PubMed]

15. Tanvir, F.; Sattar, T.; Mba, D.; Edwards, G. Identification of fatigue damage evaluation using entropy of acoustic emission waveform. SN Appl. Sci. 2019, 2, 138. [CrossRef]

16. Allen, R.V. Automatic earthquake recognition and timing from single traces. Bull. Seismol. Soc. Am. 1978, 68, 1521-1532.

17. Baer, M.; Kradolfer, U. An automatic phase picker for local and teleseismic events. Bull. Seismol. Soc. Am. 1987, 77, 1437-1445.

18. Malygin, G.A. Features of slip-band formation during the plastic straining of layered crystals. Phys. Solid State 1999, 41, 224-229. [CrossRef]

19. Küperkoch, L.; Meier, T.; Diehl, T. Automated event and phase identification. In New Manual of Seismological Observatory Practice 2 (NMSOP-2); Deutsches GeoForschungsZentrum GFZ: Potsdam, Germany, 2012; pp. 1-52.

20. Bai, F.; Gagar, D.; Foote, P.; Zhao, Y. Comparison of alternatives to amplitude thresholding for onset detection of acoustic emission signals. Mech. Syst. Signal Process. 2017, 84, 717-730. [CrossRef]

21. Pomponi, E.; Vinogradov, A.; Danyuk, A. Wavelet based approach to signal activity detection and phase picking: Application to acoustic emission. Signal Process. 2015, 115, 110-119. [CrossRef]

22. Agletdinov, E.; Merson, D.; Vinogradov, A. A New Method of Low Amplitude Signal Detection and Its Application in Acoustic Emission. Appl. Sci. 2019, 10, 73. [CrossRef] 
23. Withers, M.; Aster, R.; Young, C.; Beiriger, J.; Harris, M.; Moore, S.; Trujillo, J. A comparison of select trigger algorithms for automated global seismic phase and event detection. Bull. Seismol. Soc. Am. 1998, 88, 95-106.

24. Zhou, Z.; Cheng, R.; Rui, Y.; Zhou, J.; Wang, H.; Cai, X.; Chen, W. An Improved Onset Time Picking Method for Low SNR Acoustic Emission Signals. IEEE Access 2020, 8, 47756-47767. [CrossRef]

25. Rong, Y. Acoustic Emission Evaluation and Mechanical Property Characterization of Stainless Steel Specimens Manufactured by Powder Based 3-D Printer. Ph.D. Thesis, University of Pittsburgh, Pittsburgh, PA, USA, 2015.

26. Redl, R.; Sun, J. Ripple-Based Control of Switching Regulators-An Overview. IEEE Trans. Power Electron. 2009, 24, 2669-2680. [CrossRef]

27. Poon, N.; Liu, J.; Tse, C.; Pong, M.H. Techniques for input ripple current cancellation: Classification and implementation [in SMPS]. IEEE Trans. Power Electron. 2000, 15, 1144-1152. [CrossRef]

28. Zhang, X.; Wang, K.; Wang, Y.; Shen, Y.; Hu, H. An Improved Method of rail Health Monitoring Based on CNN and Multiple Acoustic Emission Events. In Proceedings of the 2017 IEEE International Instrumentation and Measurement Technology Conference (I2MTC), Turin, Italy, 22-25 May 2017; pp. 1-6.

29. Han, G.; Oh, T.-M.; Kim, H.; Song, K.-I.; Kim, Y.; Kwon, T.-H. Determination of Crack Signals Using the Deep Learning Technique Based on a 1D Convolutional Neural Network for Smart Detection of Structural Damage Cracking. J. Korean Soc. Hazard Mitig. 2019, 19, 1-7. [CrossRef]

30. Xin, H.; Cheng, L.; Diender, R.; Veljkovic, M. Fracture acoustic emission signals identification of stay cables in bridge engineering application using deep transfer learning and wavelet analysis. Adv. Bridg. Eng. 2020, 1, 1-16. [CrossRef]

31. Xue, W.; Guo, Y.-Q.; Zhang, X.-D. A Bank of Kalman Filters and a Robust Kalman Filter applied In Fault Diagnosis of Aircraft Engine Sensor/Actuator. In Proceedings of the Second International Conference on Innovative Computing, Informatio and Control (ICICIC 2007), Kumamoto, Japan, 5-7 September 2007.

32. Kang, S.-W.; Kim, J.-S.; Kim, G.-W. Road roughness estimation based on discrete Kalman filter with unknown input. Veh. Syst. Dyn. 2018, 57, 1-15. [CrossRef]

33. Oh, J.-S.; Shin, Y.-J.; Koo, H.-W.; Kim, H.-C.; Park, J.; Choi, S.-B. Vibration control of a semi-active railway vehicle suspension with magneto-rheological dampers. Adv. Mech. Eng. 2016, 8, 1687814016643638. [CrossRef]

34. Kim, G.-W.; Kang, S.-W.; Kim, J.-S.; Oh, J.-S. Simultaneous estimation of state and unknown road roughness input for vehicle suspension control system based on discrete Kalman filter. Proc. Inst. Mech. Eng. Part D J. Automob. Eng. 2019, $234,1610-1622$. [CrossRef]

35. Akbari, M.; Ahmadi, M. The application of acoustic emission technique to plastic deformation of low carbon steel. Phys. Procedia 2010, 3, 795-801. [CrossRef]

36. Ozevin, D. MEMS Acoustic Emission Sensors. Appl. Sci. 2020, 10, 8966. [CrossRef]

37. National Instrument Corporation. Available online: https:/ /www.ni.com/pdf/manuals/377879a.pdf (accessed on 18 June 2021).

38. Kim, M.; Lee, H.; Hong, S. Experimental determination of the failure surface for DP980 high-strength metal sheets considering stress triaxiality and Lode angle. Int. J. Adv. Manuf. Technol. 2018, 100, 2775-2784. [CrossRef]

39. Physical Acoustics Corporation. R6I-AST Sensor. 2011. Available online: http://www.physicalacoustics.com/content/literature/ sensors /Model_R6I-AST.pdf (accessed on 18 June 2021).

40. Wang, M.L.; Lynch, J.P.; Sohn, H. Sensor Technologies for Civil Infrastructures. In Applications in Structural Health Monitoring; Elsevier: Amsterdam, The Netherlands, 2014; Volume 2.

41. Phinyomark, A.; Thongpanja, S.; Hu, H.; Phukpattaranont, P.; Limsakul, P.P.A.C. The Usefulness of Mean and Median Frequencies in Electromyography Analysis. In Computational Intelligence in Electromyography Analysis-A Perspective on Current Applications and Future Challenges; IntechOpen: London, UK, 2012; pp. 195-220. 